\title{
Trend of Technological Change in Iran's Petrochemical Industry
}

\author{
Nader Dashti ${ }^{1} \&$ Hamidreza Kordlouie ${ }^{1}$ \\ ${ }^{1}$ Faculty of Accounting and Management, Islamic Azad University, Eslamshahr branch, Iran \\ Correspondence: Hamidreza Kordlouie, Apt. 12, No. 1, Kakooti alley, After Motahari junction, Shariati st., \\ 16396-48736, Tehran, Iran. Tel: 98-935-513-2200. E-mail: hamidreza.kordlouie@gmail.com
}

Received: March 27, 2012

Accepted: May 21, 2012

Published: July 1, 2012

doi:10.5539/ijef.v4n7p150

URL: http://dx.doi.org/10.5539/ijef.v4n7p150

\begin{abstract}
Nowadays, using appropriate technologies in order to make production economic and increase productivity of producing factors can be resulted optimized factors employing and also production enhancement in factories. Technological change is considered as one of the main factors of productivity growth. In this paper we have studied on the trend and bias of technological change in Iran's petrochemical industry by econometric approach from 1979 to 2008. We estimated a translog cost function in addition to equations system of cost share, using Seemingly Unrelated Regressions (SUR) approach. The results show that the rate of technological change has been -0.974 percent during the studied years. It means that there is a decrease in rate of cost of productive units during that period. Furthermore, the results indicate that technological change has been biased towards the use of more labor and material, while capital and energy have been saved.
\end{abstract}

Keywords: productivity, technological change, Translog function, petrochemical industry, Iran

\section{Introducation}

The first petrochemical factory in Iran was established in 1964 and it was a fertilizer factory in Marvdasht region. In the following years, with the installation of other factories and the application of different technology indices, petrochemical industry developed, in away that, this industry has reached to 1.2 percent of Iran's Gross Domestic Product (GDP). Although number of petrochemical factory has increased but for many reasons, resources were not been used efficiently and as a result many potential capacities has been unutilized.

A study on volume of production and number of factories in Iran's petrochemical industry shows that the problem is not the number of factories, but the problems are low factor productivity, old production methods, using modern technology incorrectly, management weakness, lack of cognition of effective elements on production and their comparative importance, etc. Thus it is inevitable to have researches on technological change analysis and to enhance productivity in petrochemical industry to optimize usage of resources. The studies on different sections of economy posed that the role of technological change to improve productivity has been significant. After Second World War, the studies on technical change have expanded in economics. Some of the famous studies are mentioned as Solow (1957, 1962), Intriligator (1965), McCarthy (1965), Jorgenson (1966), Diewert (1971), Binswanger (1974), Stevenson (1980), Romer (1990), Kant and Nautiyal (1997), Rasmussen (2000), Napasintuwong and Emerson (2002,2003), Datta and Christoffersen (2004), Hyunbae and Nadiri (2008), etc. Tendency to such researches have two mainreasons: Firstly, supply increasing in industrial products in comparison to their demand caused decreasing in prices and also in industrial section's revenue. It also caused troubles in this section. This attracted economists to discover the reasons of the growth, while one of the main reasons or the most important one was technical change. Secondly, there was a shortage of industrial materials in developing countries. Therefore, according to the aforesaid reasons, technical change was considered as a major reason of productivity growth (Hayami and Godo, 2005).

Technological change in petrochemical industry is also one of the main elements of productivity growth. In this respect, it is necessary to recognize the technology of petrochemical industry, bias and rate of growth to modify and reinforcement of mentioned industry condition. So, the goal of this study is analysis of different aspects of technological change in Iran's petrochemical industry during the years 1979-2008.

\section{Method}

\subsection{Methodology}

In production process, production technology is the relation between inputs and output, which can be illustrated by production function (Chambers, 1988). The production structure and technological change can be surveyed by production function or dual cost function; it is in any industry such as petrochemical industry. Direct estimation of 
production function will be appropriate if amount of output is determined endogenously, while for exogenous amount of output cost function is preferred (Kant and Nautiyal, 1997).

In order to choose the most proper functional form among all functional forms, translog functional form has been chosen. Because it is widely used in similar researches and also is flexible enough. Furthermore, it has some special theoretical and statistical characteristics like derivation of factor demand functions easily.

General form of cost function regarding time trend (T) variable is as follow (Rasmussen, 2000):

$$
C=f\left(P_{l}, P_{k}, P_{e}, P_{m}, Q, T\right)
$$

In which $\mathrm{P}_{1}, \mathrm{P}_{\mathrm{k}}, \mathrm{P}_{\mathrm{e}}$ and $\mathrm{P}_{\mathrm{m}}$ are prices of labor, capital, energy and material respectively. $\mathrm{Q}$ is value of product and $\mathrm{C}$ is cost. So, translog cost function is written as follow:

$$
\begin{gathered}
\operatorname{LnC}=v+\sum_{i} a_{i} \operatorname{Ln} P_{i}+a_{q} \ln Q+\frac{1}{2} \sum_{i} \sum_{j} b_{i j} \operatorname{Ln} P_{i} \operatorname{Ln} P_{j} \\
+\sum_{i} b_{i q} \operatorname{Ln} Q \ln P_{i}+\frac{1}{2} b_{q}(\ln Q)^{2}+b_{t} T+\frac{1}{2} b_{t t}(T)^{2} \\
+\sum_{i} b_{t i}\left(\ln P_{i}\right) T+b_{q t}(\ln Q) T \\
i, j=k, l, e, m
\end{gathered}
$$

Factor cost shares can be obtained by partial derivation of translog function with respect to i-th input price .So:

$$
\begin{gathered}
\frac{\partial \ln C}{\partial \ln P_{i}}=\frac{\partial C}{\partial P_{i}} \frac{P_{i}}{C}=\frac{x_{i} P_{i}}{C}=S_{i} \\
S_{i}=a_{i}+\sum_{j} b_{i j} \ln P_{j}+b_{i q} \ln Q+b_{i i} T
\end{gathered}
$$

In which, $C=\sum P_{i} X_{i}, \mathrm{~S}_{\mathrm{i}}$ is cost share of $\mathrm{i}$-th input and $\mathrm{X}$ refers to amount of factor.

In order to ensure that the underlying cost function is well-behaved, the cost function must be homogeneous of degree one in input prices, given output. Then, liner homogeneity in factor prices and symmetry imposes the following restrictions:

$$
\sum a_{i}=1 \quad \sum b_{i j}=0 \quad \sum b_{i q}=0 \quad b_{i j}=b_{j i}
$$

Rate of technological change cadn be obtained by derivation of cost function with respect to time (Datta and Christoffersen, 2004 and Kant and Nautiyal, 1997):

$$
\stackrel{\circ}{C}=\frac{\partial \ln C}{\partial T}=b_{t}+b_{t t} T+\sum b_{t i} \ln P_{i}+b_{q t} \ln Q
$$

It shows that technological change can be divided in three elements:

1- pure technical change $\left(b_{t}+b_{t t} T\right)$

2- non-neutral technical change $\left(\Sigma b_{t i} \ln P_{i}\right)$

3- scale-augmenting technical change $\left(\mathrm{b}_{\mathrm{qt}} \ln \mathrm{Q}\right)$

The first element - pure technical change- has no relation with inputs, amount of output and factor prices. It is a fixed part of function and its change causes cost function moving towards up or down. If it is negative, cost function goes down and it indicates positive technological change.

Interaction of factors during time is in second element. In other words, it shows the effects of technological change on factors during the time. It shows any substitution or saving factors. Changing this element results slope changing of cost curve.

Third element is the effect of technological change on capacity of institute. Clearly scale-augmenting technological change causes Economies of scale, because of increasing in production. It also decreases cost and leads to cost function shift.

In cost function, return to scale (scale elasticity) is determined as follow: 


$$
E=\left[\frac{\partial \ln \mathrm{C}}{\partial \ln \mathrm{Q}}\right]^{-1}=\left(\mathrm{a}_{\mathrm{q}}+\mathrm{b}_{\mathrm{q}} \ln \mathrm{Q}+\sum_{\mathrm{i}} \mathrm{b}_{\mathrm{iq}} \ln \mathrm{P}_{\mathrm{i}}+\mathrm{b}_{\mathrm{q}} \mathrm{T}\right)^{-1}
$$

Returns to scale refers to changes in output subsequent to a proportional change in all inputs (where all inputs increase by a constant factor). If output increases by that same proportional change then there are constant returns to scale (CRS). If output increases by less than that proportional change, there are decreasing returns to scale (DRS). If output increases by more than that proportion, there are increasing returns to scale (IRS).

Stevenson (1980) believes that technological change may have bias to factor and scale characteristics of production. In case of technical progress, factor bias is as follow:

$$
I_{b i}=\frac{\partial S_{i}}{\partial T}
$$

If $\mathrm{I}_{\mathrm{bi}}>0$, technological change results to use input $\mathrm{i}$ more. If $\mathrm{I}_{\mathrm{bi}}<0$, technological change saves input $\mathrm{i}$. If $\mathrm{I}_{\mathrm{bi}}=0$ then it has no effect on using input $i$. Scale bias is calculated by derivation of the phrase in bracket:

$$
S E_{i}=\frac{\partial^{2} \ln C}{\partial \ln P_{i} \cdot \partial \ln Q}=\frac{\partial S_{i}}{\partial \ln Q}
$$

If $\mathrm{SE}_{\mathrm{i}}>0$, increasing of production scale, leads to use input $\mathrm{i}$ more. If $\mathrm{SE}_{\mathrm{i}}<0$, it leads to use input $\mathrm{i}$ less. If $\mathrm{SE}_{\mathrm{i}}=0$ it has no effect on using input $\mathrm{i}$.

Anyhow, cost function system can be estimated if data and information is available. Although parameters of basic cost function are being estimated by Ordinary Least Squares (OLS) method, but it is not included cost share equations. A suitable method to estimate such systems is Seemingly Unrelated Regression (SUR). Since value shares sum to using, the sum of the disturbances across any three equations is zero at all observations (Baltagi, 2005). Hence, to avoid singularity of the covariance matrix any one of the four share equations can be dropped, i.e., three can be estimated and the forth is automatically determined (Kant and Nautiyal, 1997). We drop energy share equation. Eventually, according to the methodology, technological change is being analyzed.

\subsection{Sources of Data and Structure of Variables}

The data were collected from various editions of the Iranian reports on industrial workshops and different volume of the Wholesale Price Index in Iran. We have adopted 1997 as base year to converting nominal data to real data. Output is the value of aggregate output produced during the year. This implies that no change in the stock of output has taken place. The capital expenditure is computed as the user cost of capital multiplied by the capital stock. In order to calculate the user cost of capital, we used $\mathrm{Puk}=(\mathrm{r}+\mathrm{P}) \mathrm{Pi}$, where $\mathrm{r}$ is the long run interest rate, $\mathrm{P}$ is the depreciated rate of capital assumed to be $5.5 \%$ by year and $\mathrm{Pi}$ is the investment deflator.

Total cost is the sum of the cost of labor, capital, material and energy. For labor input, the number of persons employed and the wage calculated for emoluments per person employed have been used for model estimation. The price of labor is obtained as the ratio of total compensation to labor divided by the number of workers. Fuel cost is the cost of all types of fuel used for production. We add fuel cost to electricity cost to obtain energy cost. The price of fuel is obtained by taking a weighted average of all types of fuel prices. The price of energy is obtained by taking a weighted average of fuel and electricity price. The cost share of labor, capital, material and energy are obtained by dividing the corresponding cost by the total cost.

\subsection{Test of Stationarity}

To use time series data in estimation of model, we need to examine the series for stationarity. If a time series is stationary, its mean, variance, and autocovariance (at various lags) remain the same no matter at what point we measure them; that is, they are time invariant. If series are nonstationary, $\mathrm{F}$ and $\mathrm{t}$ statistics are not valid and estimated model is not reliable (Gujarati, 2004).

Results of the Augmented Dickey-Fuller (ADF) test shows that all variables have unit root and after first difference, they become stationary (table 1). Also the test shows stationarity of residuals. Thus, spurious regression is rejected and the results of estimation are reliable (table 2). 
Table 1. Results of Augmented Dickey-Fuller Unit Root Test on Variables

\begin{tabular}{ccccc}
\hline \multirow{2}{*}{ Variable* } & \multirow{2}{*}{ ADF Statistic } & \multicolumn{3}{c}{ Mackinnon critical values } \\
\cline { 3 - 5 } & & $\mathbf{1 0 \%}$ & $\mathbf{5 \%}$ & $\mathbf{1 \%}$ \\
\hline D(LC) & -3.947 & -2.638 & -2.998 & -3.752 \\
D(LPL) & -3.646 & -2.632 & -2.986 & -3.424 \\
D(LPK) & -4.181 & -2.632 & -2.986 & -3.424 \\
D(LPE) & -5.753 & -2.632 & -2.986 & -3.424 \\
D(LPM) & -3.561 & -2.635 & -2.991 & -3.737 \\
D(SL) & -3.164 & -2.635 & -2.991 & -3.737 \\
D(SK) & -4.427 & -2.632 & -2.986 & -3.424 \\
D(SE) & -4.736 & -2.632 & -2.986 & -3.424 \\
D(SM) & -4.902 & -2.632 & -2.986 & -3.424 \\
D(LQ) & -4.044 & -2.635 & -2.991 & -3.737 \\
\hline
\end{tabular}

* Ln of variables in equations no. $1 \& 3$

Table 2. Results of Augmented Dickey-Fuller Unit Root Test on Residuals

\begin{tabular}{ccccc}
\hline \multirow{2}{*}{ Variable } & \multirow{2}{*}{ ADF Statistic } & \multicolumn{3}{c}{ Mackinnon critical values } \\
\cline { 3 - 5 } & & $\mathbf{1 0 \%}$ & $\mathbf{5 \%}$ & $\mathbf{1 \%}$ \\
\hline RESID 01 & -4.361 & -2.629 & -2.981 & -3.711 \\
RESID 02 & -3.407 & -2.629 & -2.981 & -3.711 \\
RESID 03 & -3.023 & -2.629 & -2.981 & -3.711 \\
RESID 04 & -3.590 & -2.629 & -2.981 & -3.711 \\
\hline
\end{tabular}

\section{Results}

The parameter estimates of the translog cost function along with the associated cost share equations are presented in table 3. Many significant variables and high value of $\mathrm{R}^{2}$ are signs of good estimation. Durbin Watson (D.W) statistic shows that there is no autocorrelation in estimated model.

Table 3. Results of Parameter Estimates

\begin{tabular}{|c|c|c|c|c|c|}
\hline Parameter & Coefficient & t-Statistic & Parameter & Coefficient & $\mathrm{t}$-Statistic \\
\hline $\mathrm{V}$ & -113.199 & -4.542 & blm & -0.016 & -0.625 \\
\hline al & 0.992 & 1.834 & bke & -0.050 & -1.947 \\
\hline ak & -0.294 & -0.855 & bkm & -0.074 & -4.309 \\
\hline ae & -0.590 & $-1 / 843$ & bem & -0.050 & -1.744 \\
\hline $\mathrm{am}$ & 0.304 & 0.426 & $\mathrm{btt}$ & -7.051 & -0.028 \\
\hline aq & 14.978 & 4.969 & blt & 0.005 & 2.689 \\
\hline $\mathrm{bt}$ & -1.059 & -4.396 & bkt & -0.003 & -1.701 \\
\hline $\mathrm{bq}$ & -0.811 & -3.296 & bet & -0.015 & -2.070 \\
\hline bll & 0.095 & 3.498 & bmt & 0.002 & 0.616 \\
\hline bkk & 0.102 & 8.756 & bqt & -0.070 & -3.670 \\
\hline bee & -0.253 & -0.358 & blq & 0.089 & 4.280 \\
\hline bmm & 0.063 & 1.762 & bkq & -0.068 & -3.439 \\
\hline blk & -0.042 & -3.426 & beq & -0.114 & -2.511 \\
\hline ble & 0.057 & 1.834 & bmq & 0.162 & 4.774 \\
\hline $1.74=0.96$ & & $=\mathrm{R} 2$ & & $=\mathrm{R}$ & \\
\hline
\end{tabular}




\subsection{Rate of Technological Change}

The study of technological change during the studied years clarify that by the passage of time and technology progress in petrochemical industry make decreasing in rate of cost change. According to equation 6, rate of technological change since 1979 to 2008 is -0.974 . It means that rate of decreasing in cost of production has been $0.974 \%$ in average each year. Though, rates of years are different in table 4, but negative sign means decreasing in cost rate during the time. So, calculations confirm that technology progress has decreased rate of cost change of petrochemical factories.

Table 4. Rate of Technological Change

\begin{tabular}{ll|ll}
\hline Year & Rate of Technological Change (percent) & Year & Rate of Technological Change (percent) \\
\hline 1979 & -0.988 & 1994 & -0.968 \\
1980 & -1.023 & 1995 & -0.974 \\
1981 & -1.032 & 1996 & -0.970 \\
1982 & -1.036 & 1997 & -0.948 \\
1983 & -1.024 & 1998 & -0.947 \\
1984 & -1.023 & 1999 & -0.939 \\
1985 & -1.029 & 2000 & -0.928 \\
1986 & -1.042 & 2001 & -0.926 \\
1987 & -1.034 & 2002 & -0.918 \\
1988 & -1.038 & 2003 & -0.908 \\
1989 & -1.014 & 2004 & -0.898 \\
1990 & -1.009 & 2005 & -0.898 \\
1991 & -1.017 & 2006 & -0.885 \\
1992 & -1.018 & 2007 & -0.883 \\
1993 & -1.004 & 2008 & -0.881 \\
\hline \multicolumn{2}{l}{ Average of period=-0.974\% }
\end{tabular}

Average of period $=-0.974 \%$

\subsection{Return to Scale}

Study of return to scale indicates that it has been increasingly during the studied years in average it is 1.26 . Thus, capacity increasing of productive units leads to Economies of scale.

Table 5. Return to Scale

\begin{tabular}{ll|ll}
\hline Year & Return to Scale & Year & Return to Scale \\
\hline 1979 & 1.231 & 1994 & 0.988 \\
1980 & 1.132 & 1995 & 1.108 \\
1981 & 1.552 & 1996 & 1.164 \\
1982 & 1.452 & 1997 & 1.165 \\
1983 & 1.332 & 1998 & 1.027 \\
1984 & 1.219 & 1999 & 1.090 \\
1985 & 1.201 & 2000 & 1.138 \\
1986 & 1.202 & 2001 & 1.193 \\
1987 & 1.248 & 2002 & 1.385 \\
1988 & 1.213 & 2003 & 1.482 \\
1989 & 1.171 & 2004 & 1.664 \\
1990 & 1.129 & 2005 & 1.556 \\
1991 & 1.066 & 2006 & 1.608 \\
1992 & 0.977 & 2007 & 1.662 \\
1993 & 0.969 & 2008 & 1.683 \\
\hline \multicolumn{3}{l}{ Average of period=1.267 }
\end{tabular}

\subsection{Factor and Scale Bias}

The results of factor and scale bias (equations $8 \& 9$ ) are presented in table 6 . Positive signs of bias of labor and material factors show that labor and material using has increased during the studied time. It means that if the prices of other factors are constant, the cost shares of labor and material increases during the time. On the other hand, 
negative sign of bias of energy, indicates that using modern technologies causes less using of energy in productive units. Also, negative sign of capital shows that using advanced machineries leads to capital saving.

According to scale bias figures, increase in production scale will lead labor and material to be used increasingly. It means that expansion in size of productive units causes tendency to use more labor and material. Meanwhile, capital and energy factors have been used decreasingly.

Table 6. Factor and Scale Bias

\begin{tabular}{lll}
\hline Input & Factor Bias & Scale Bias \\
\hline Labor & 0.005 & 0.089 \\
Capital & -0.003 & -0.068 \\
Energy & -0.015 & -0.114 \\
Material & 0.002 & 0.162 \\
\hline
\end{tabular}

\section{Discussion}

Estimation of cost function and cost share equations by SUR method, show that the aforementioned function explains the status of petrochemical factories accurately; because many of coefficients are significant and $\mathrm{R}^{2}$ is high. The sign belongs to rate of technological change shows that during time, rate of cost in productive units has decreased. Therefore we see that using new and advanced technology cause better cost change during the studied time. So, it is expected to have more economic production process in petrochemical industry by using of this kind of technologies.

According to the results, scale elasticity statistic indicates increasing return to scale in Iran's petrochemical industry. In this respect, petrochemical production increases more than the proportional change in all inputs. Then, per unit cost will be decreased and as a result Economies of scale is appeared in petrochemical production process. So, it is recommended to use the ways to increase the capacity of productive units

In period of study, result assessment of factor and scale bias in petrochemical industry show adoption of research findings. Considering positive factor bias and also scale bias of labor and material, and on the other hand, high cost shares of these inputs out of total cost of inputs in productive units, managers ought to be encouraged to increase productivity of the mentioned inputs to decrease production cost. Moreover this kind of technological change diminishes dependence on capital and energy and related costs.

\section{References}

Baltagi, B. H., \& Rich, D. P. (2005). Skilled-biased Technical Change on US manufacturing: a general index approach. Journal of Econometrics, 126, 549-570. http://dx.doi.org/10.1016/j.jeconom.2004.05.013

Binswanger, H. P. (1974). A Microeconomic Approach to Induced Innovation. Economic Journal, 84, 940- 958. http://dx.doi.org/10.2307/2230575

Chambers, R. G. (1988). Applied Production Analysis: A Dual Approach. Cambridge University Press.

Datta, A., \& Christoffersen, S. (2004). Production Costs, Scale Economies and Technical Change in U.S. Textile and Apparel Industries. School of Business Administration,Philadelphia university.

Diewert, W. E. (1971). An Application of the Shephard Duality Theorem: A Generalized Leontief Production Function. The Journal of Political Economy, 79(3), 481-507. http://dx.doi.org/10.1086/259764

Gujarati, N. (2004). Basic Econometrics (4th ed.). McGraw-Hill.

Hayami, Y., \& Godo, Y. (2005). Development Economics. Oxford University Press. http://dx.doi.org/10.1093/0199272700.001.0001

Hyunbae, C., \& Ishaq Nadiri, M. (2008). Decomposing Productivity Growth in the U.S. Computer Industry. The Review of Economics and Statistics, 90, 174-180. http://dx.doi.org/10.1162/rest.90.1.174

Intriligator, M. D. (1965). Embodied Technical Change and Productivity in the United States, 1929-1957. Review of Economics and Statistics, 47, 65-70. http://dx.doi.org/10.2307/1924123

Iranian statistical center. Iranian report on industrial workshops, various issues.

Jorgenson, D. W. (1966). The Embodiment Hypothesis. Journal of Political Economy, 74, 1-17. http://dx.doi.org/10.1086/259105 
Kant, S., \& Nautiyal, J. C. (1997). Production Structure, Factor Substitution, Technical Change, and Total Factor Productivity. Canadian Journal of Forest Research, 27, 701-710. http://dx.doi.org/10.1139/x96-190

McCarthy, M. D. (1965). Embodied and Disembodied Technical Progress in the Constant Elasticity of Substitution Production Function. Review of Economics and Statistics, 47, 71-75. http://dx.doi.org/10.2307/1924124

Napasintuwong, O., \& Emerson, R. D. (2002). Induced Innovations and Foreign Workers in U.S. Agriculture. Selected paper prepared for presentation of the American Agricultural Economics Association Annual Meeting, Califonia.

Napasintuwong, O., \& Emerson, R. D. (2003). Farm Mechanization and the Farm Labor Market: A Socioeconomic Model of Induced Innovation. Selected paper prepared for presentation of the Southern Agricultural Economics Association Annual Meeting. Mobile, A Labama.

Rasmussen, S. (2000). Technological Change and Economies of Scale in Danish Agriculture. The Royal Eterinary and Agricultural University KVL, Copenhagen.

Romer, P. M. (1990). Endogenous Technological change. Journal of Politiocal Economy, 98, 71-102. http://ssrn.com/abstract=1506720

Solow, R. M. (1957). Technical Change and the Aggregate Production Function. Review of Economics and Statistics, 39, 312-320. http://dx.doi.org/10.2307/1926047Solow, R. M. (1962). Technical Progress, Capital Formation, and Economic Growth. American Economic Review, 52, 76-86,

Stevenson, R. (1980). Measuring Technological Bias. American Economic Review, 70, 162-173. 